This is an electronic reprint of the original article. This reprint may differ from the original in pagination and typographic detail.

Author(s): Ruuska, Katharina

Title: $\quad$ Between ideologies and realities : Multilingual competence in a languagised world

Year: $\quad 2016$

Version:

Please cite the original version:

Ruuska, K. (2016). Between ideologies and realities : Multilingual competence in a languagised world. Applied Linguistics Review, 7(3), 353-374.

https://doi.org/10.1515/applirev-2016-0015

All material supplied via JYX is protected by copyright and other intellectual property rights, and duplication or sale of all or part of any of the repository collections is not permitted, except that material may be duplicated by you for your research use or educational purposes in electronic or print form. You must obtain permission for any other use. Electronic or print copies may not be offered, whether for sale or otherwise to anyone who is not an authorised user. 
Katharina Ruuska*

\title{
Between ideologies and realities: Multilingual competence in a languagised world
}

DOI 10.1515/applirev-2016-0015

\begin{abstract}
Recent developments in sociolinguistics and applied linguistics have put emphasis on the contrast between ideologies of distinct 'languages' and the multifaceted reality of linguistic practices. This article argues that recent usage-based reconceptualisations of the notions of competence and repertoire can help paint a more complex picture of the relationship between monolingual 'ideologies' and diverse linguistic 'realities'. Drawing on data from interviews with highly proficient adult speakers of Finnish as a second language, I explore some aspects of how speakers' competence can be understood as shaped by language use, and what role linguistic ideologies, social expectations and speakers' environments play in this process. I conclude that, in a languagised world, the ability to keep 'languages' apart and to successfully display monolingual competence can be seen as part of multilingual speakers' competence. In this way, a usage-based perspective on competence enables us to treat 'languages' as ideological constructs, while at the same time acknowledging their 'real' effects on speakers' competence and language use.
\end{abstract}

Keywords: multilingualism, competence, ideology, usage-based SLA, Finnish as a second language

\section{Introduction}

In recent years, the notion of 'language' as a natural and bounded entity has come under heavy scrutiny within sociolinguistics and applied linguistics (e.g., Blommaert 1999; Makoni and Pennycook 2005; Heller 2008). This has also led to a critical review of the assumptions underlying analysis and research practice in these fields. In particular, scholars have drawn attention to the analytical gap between the ideological assumption of distinct 'languages' and the multifaceted reality of linguistic practices which often includes language use across language 'boundaries'. Languages have accordingly been described as "sociocultural or

*Corresponding author: Katharina Ruuska, University of Jyväskylä, Jyväskylä, Finland, E-mail: katharina.m.ruuska@students.jyu.fi 
ideological constructions which match real-life use of language poorly” (Jørgensen et al. 2011: 23). While it is certainly true that many instances of 'real' language use have been (and are still) ignored, misinterpreted or depreciated due to an ideologically biased perspective in the study of language, it is, however, questionable whether fluid practices across language boundaries can be seen as somehow more 'natural' or 'real' than practices that strongly orient toward the ideological construct of 'language'. This is why Canagarajah (2011: 3) calls for scepticism toward "this new binary - multilingual and monolingual" and for paying attention to the possible limitations to multilingual communication.

This article argues that recent usage-based reconceptualisations of 'competence' and the related notion of 'repertoire' can help paint a more complex picture of the relationship between what is often simply depicted as a mismatch between monolingual 'ideologies' and multilingual 'realities'. A usage-based understanding of language (learning) (see, e. g., Ortega 2014 for an overview) proposes an understanding of competence as shaped by the interaction between cognitive constraints and engagement with language in everyday life. In this view, studying speakers' linguistic practices as well as their sociolinguistic environments and the norms valid in these environments is vital for gaining an understanding of the specific kind of competence they develop, including linguistic resources and the cultural and communicative rules linked to them. I argue that, from such a perspective, 'languages' can be reintroduced into the analysis: not as an a priori category but as something that can become part of a speaker's competence through the way language use is organised in a specific social context.

In Section 5, I explore such a social context as it is experienced by speakers themselves. Drawing on data from interviews with highly proficient adult speakers of Finnish as a second language, I ask what specific ideologies, orientations and sociolinguistic expectations the studied speakers experience as relevant with regard to their linguistic practices and the development of linguistic competence. First, however, I will take a more detailed look at the consequences the deconstruction of 'language' as a natural and bounded entity has for the conceptualisation of individual language knowledge. In other words: what is it that speakers know if it is not 'a language'?

\section{Usage-based perspectives on multilingual competence}

Blommaert and Backus (2011) have revisited the notions of 'repertoire' and 'communicative competence', found in the early sociolinguistic works of 
Gumperz and Hymes. Gumperz referred to repertoire as the "totality of linguistic resources [...] available to members of particular communities” (1986 [1972]: 20), emphasizing that what would be considered distinct languages or dialects from the viewpoint of grammar form a whole in the repertoire of a community (Busch 2012: 504). Increasingly unpredictable linguistic trajectories and emerging 'superdiverse' contexts have, however, highlighted the problems with a definition of repertoire "as the static, synchronic property of a 'speech community"” (Blommaert and Backus 2011: 24). Blommaert and Backus thus suggest a shift in perspective toward individual repertoires, seeing repertoire as the result of biographical trajectories and as made up of resources "functionally distributed in a patchwork of competences and skills” (Blommaert and Backus 2011: 2). ${ }^{1}$ They also emphasise how 'repertoire' is closely connected to "that other key notion in sociolinguistics, 'communicative competence' - the knowing what and knowing how to use language” (Blommaert and Backus 2011: 3). Introduced by Hymes (1972 [1971]) as a reaction to Chomsky's conceptualisation of 'competence' as the ideal (native) speaker-hearer's knowledge of a 'language system', the term drew attention to the sociocultural aspects of language knowledge. Sociocultural knowledge of language use and knowledge of grammar were seen as interlinked, and Hymes insisted on the importance of conceptualising competence "beyond any simple distinction, or dichotomy, between grammar and use” (Hymes 1992: 51). Yet, linguistic and communicative competence proceeded to be theorised separately for the most part (Blommaert and Backus 2011: 5), in theoretical linguistics and sociolinguistics respectively.

In Blommaert and Backus' view, the recent rise of usage-based approaches in linguistics (or 'usage-based linguistics', UBL) has brought about a framework for rethinking 'competence'. From a usage-based perspective, 'language' is not considered an independent system but is seen as emerging from concrete instances of communication, appearing as a "process rather than an object" (Ortega 2014: 40). Linguistic competence is thus not described as the command of an abstract language 'system' but is defined as a dynamic and evolving "inventory of linguistic resources” (Blommaert and Backus 2011: 7) that are cognitively entrenched through language use (and can also be 'unlearned' again). In Blommaert and Backus' view these resources comprise not only the "traditional linguistic elements of sounds, words and patterns, but [...] anything that people use to communicate meaning" (2011: 7). As a consequence, linguistic and communicative competence are not treated as separate concepts but are seen as two sides

1 A focus on individual repertoires has been developed elsewhere, too (e. g., Busch 2012; Rymes 2010). 
of the same coin. In this view, the qualifier 'communicative' can be dropped and 'competence' becomes a holistic term, comprising "everything that has always been included in linguistic competence as well as discourse patterns and cultural behavioral patterns" (Blommaert and Backus 2011: 7). With regard to the status of 'language' in this framework, 'a language' cannot be seen as psychological reality but rather is a question of analytical abstraction, "a convenient way to refer to the cumulative inventory of resources shared by most people in a "community"' (Blommaert and Backus 2011: 8). What is 'real' are the repertoires that "we have and can deploy in social life: biographically assembled patchworks of functionally distributed communicative resources, constantly exhibiting variation and change." (Blommaert and Backus 2011: 23). This also means that communities and individual speakers can only be 'monolingual' by virtue of abstraction and generalisation, and, conversely, a conventional understanding of bilingualism is no more than "a salient, special case of the general phenomenon of linguistic repertoire" (Hymes 1986 [1972]: 38).

A usage-based approach to language knowledge and the issue of 'language' has also been discussed in the more specific context of additional language learning. Hall et al. (2006) have revisited the concept of "multicompetence", going back to Vivian Cook's work in the nineties (Cook 1991, 1992, 1999). Cook developed the concept to challenge the monolingual bias of a native speakerbased notion of 'competence', arguing that this notion of competence is not able to truthfully represent the language knowledge of most people, since most people are multilinguals. He claimed that the knowledge of different languages is not organised in terms of separate competences in the mind of the speaker but forms one "wholistic multicompetence" (Cook 1992), and that the cognition of multicompetent speakers is qualitatively different from that of monolingual or monocompetent speakers (Cook 1999). By acknowledging all the linguistic resources learners have, not just the ones in the 'target language', and by seeing L2 users as "speakers in their own right” (Cook 1999: 195) who should not be conceptualised as 'failed' monolingual native speakers, Cook's approach contributed substantially to challenging what Ortega (2014: 34) calls "the deficit approach dominant in SLA". However, the concept of 'multicompetence' is not unproblematic, especially when taking into account the recent insights into the constructedness of 'languages'. For instance, the claim that multi- and monocompetence are qualitatively different presupposes the possibility of a 'truly monolingual' competence and builds on the assumption of "homogeneity of language knowledge across speakers and contexts" (Hall et al. 2006: 225). In light of the above, it is clear that such a distinction cannot be upheld. The linguistic repertoires of speakers and groups are always already diverse in themselves, comprising resources associated with different registers (or 'dialects' 
or 'languages'). Conversely, speakers can never be competent in all the registers attributed to a 'language'. ${ }^{2}$ From a usage-based perspective, cognitive differences between language users are then not based on the number of 'language systems' available to them but on the amount and quality of their experiences of language use. In other words, differences between speakers are based on divergent individual experiences, not on a particular speaker status (e. g., monolingual, bilingual, trilingual; Hall et al. 2006: 230).

Ortega's (2014) discussion of the potential for a "bi/multilingual turn" in SLA is equally committed to a usage-based perspective. After the "social turn in SLA" (Block 2003) has already highlighted the monolingual bias and a range of other problematic assumptions in mainstream linguistic-cognitive SLA - notably the concept of 'nativeness' - Ortega suggests it is time for a profound theoretical change in the form of "a strategic theoretical commitment to UBL as a helpful move that supports a desirable bi/multilingual turn for linguistic-cognitive SLA research communities" (Ortega 2014: 39). Like Hall et al. (2006), Ortega argues that it is not categorical concepts such as 'native speaker' that are crucial for understanding the development of language knowledge, but the specificities of individual engagement with language. Since this engagement with language always takes place in a social environment, Ortega emphasises the necessity of integrating social perspectives and usage-based linguistic-cognitive perspectives, and stresses that "agency, identity, and power are paramount in understanding the link between opportunities for actual language use [...] and successful linguistic development, in both adult and child additional-language learning” (2014: 47).

The above discussion shows that the idea of 'language' as an abstract system or a bounded entity is incompatible with a usage-based perspective of competence and language learning. 'Resources', 'repertoires' and a sociolinguistically informed understanding of 'competence' seem to be more adequate notions for describing what it is that speakers 'have' or know. Moreover, if competence is understood as inherently dynamic, its development is never 'complete' or 'finished' (Blommaert and Backus 2011: 23) and a qualitative distinction between 'learners' and 'speakers' becomes difficult to maintain. From this perspective, 'languages' appear indeed as ideological constructions unable to capture the diverse and dynamic reality of linguistic knowledge. However, the role that

2 This is already emphasised by Hymes (1972 [1971]: 282): “[It] cannot be assumed that the formal possibilities of a system and individual knowledge are identical; a system may contain possibilities not part of the present knowledge of a user [...]. Nor can it be assumed that the knowledge acquired by different individuals is identical, despite identity of manifestation and apparent system.” 
'languages' play as cultural constructs that language users in many contexts orient to, i. e. their sociocultural reality, should not be overlooked. While research has shown (e.g., Makoni and Pennycook 2005) that the idea of separate 'languages' is far from universal and thus misleading when applied in blanket fashion to different contexts of language use, it certainly is a central cultural construct at least in a range of Western settings. What is needed, then, is a way of analysing and theorising linguistic processes in these settings that avoids reverting to conceptualisations of 'languages' as ontologically 'real' entities and that at the same time acknowledges what can be called their sociocultural 'reality'. In the following section, I explore to what extent a usage-based perspective can provide an answer to this challenge.

\section{Reintroducing 'language' from a usage-based perspective}

A usage-based understanding of competence tightly links language learning processes to speakers' engagement with language. Concepts like frequency and salience become crucial in explaining how quickly and permanently linguistic resources (as well as discourse patterns and sociocultural rules of language use) are entrenched (see Blommaert and Backus 2011: 6). ${ }^{3}$ This means that, while language knowledge can be seen as inherently dynamic, i. e. continually adapting to changing requirements and contexts of language use, it is also "subject to a variety of stabilizing influences that are tied to the constancy of individuals' everyday lived experiences, and more generally, to more encompassing societal norms that value stability" (Hall et al. 2006: 229). In other words, from a usage-based perspective, stable features of linguistic competence have to be seen as the product of stable patterns of language use that speakers are exposed to in their social environments.

With respect to the relationship between competence and 'languages', this means that both what is perceived as 'monolingual' language use (i. e. the use of one 'language' at a time) and practices across 'language boundaries' (e. g., code-switching or translanguaging) are learnt through language use. In her study of 'language

3 From a usage-based perspective, this is probably also true for the 'unlearning' of resources, as Lowie et al. (2009: 125) point out: "[L]anguage acquisition and language attrition are manifestations of similar mechanisms of change, and the multilingual system can develop in many different ways, not only through the acquisition of new languages or dialects but also through the decline of language skills due to non-use or injury.” 
mixing' in infant bilingualism, Lanza (2004 [1997]: 70) argues that the question whether bilingual children's linguistic competence is organised in terms of one or two 'systems' might be the wrong question to ask. Instead, researchers should pay attention to how children's 'language mixing' relates to the concrete input given as well as to the linguistic norms present in the context of their language socialisation (Lanza 2004 [1997]: 69). This means that some children "are actually socialized into code-switching” (Lanza 2004 [1997]: 69), whereas others are not. Canagarajah (2011) notes that, despite evidence of this kind, many studies on multilingual language use seem to assume that translanguaging, i. e. sense-making discursive practices across 'language' boundaries (see García 2009: 45), is "an intuitive capacity for which multilinguals are naturally endowed” (Canagarajah 2011: 9). Drawing on his own case study of a writing class, he shows that multilingual students' translanguaging proficiency was not 'natural' but developed as they analysed, discussed and redrafted their translingual writings. All this suggests that multilingual speakers can differ significantly from one another, not only in terms of the 'content' of their competence (i. e. the linguistic resources available to them), but also in terms of how this content is structured and what rules for its use speakers have internalised and orient to in their language use. This ties in well with a usage-based approach to language learning. If the development of linguistic competence is seen as tightly linked to the sociocultural and linguistic environment, sociocultural 'realities' will in some way be reflected in the cognitive 'reality' of a speaker. For instance, a social and cultural environment that is built around and actively promotes monolingualism or an understanding of multilingualism as 'multiple monolingualism' (e. g., Makoni and Pennycook 2005; Heller 2009; Jørgensen 2012) will lead to the development of a different kind of competence than a context with a strong "plurilingual tradition" (Canagarajah 2009). Linguistic competence can then be seen as the result of experiences (at least in part) afforded by sociocultural constructs like 'languages'.

These same sociocultural constructs also link a perspective on competence as a cognitive phenomenon to a perspective on competence as a social ascription. This is because an important part of speakers' experience with language in the social world is how their language use is interpreted and evaluated by others on the basis of a range of beliefs about language and how it should be used. What is considered culturally appropriate or competent will of course differ widely from context to context (the starting point for Hymes' “ethnography of speaking”), and definitions of competence are constantly re-negotiated in the face of social and economic changes (see Heller 2003). Moreover, Blommaert et al. (2005) have argued that an understanding of multilingual competence as the property of an individual (as suggested by the phrase of 'having' competence in one or multiple languages) obscures the ways in which this competence is enabled or disabled by the social and geographical environment. For instance, a multilingual speaker of Bulgarian, 
Turkish and Russian in Belgium can still be constructed as 'speaking no language' in an encounter with members of the majority population who do not share those linguistic resources (Blommaert et al. 2005: 210). It is therefore important to pay attention to both the potential a speaker's competence entails and to how this speaker is positioned with respect to her/his competence in a given context (see Blommaert et al. 2005: 211), especially if this context differs from the contexts in which competence was initially developed (like, e. g., in the case of migration).

For a usage-based perspective on language learning this means that the concrete opportunities for engagement with language will be shaped by the distribution of resources in the sociolinguistic environment as well as, more indirectly, by the broader sociocultural values attributed to different kinds of linguistic competence. Because communicative repertoires are never fixed or complete, experiences of "what counts as competence in real environments" (Blommaert et al. 2005, emphasis in original) are an important influence on the dynamic development of linguistic competence. Learning trajectories are connected to power and social acceptability, and repertoire can also be understood as "a collection of resources our subject had to accumulate and learn in order to make sense to others" (Blommaert and Backus 2011: 23, emphasis in original). Although local norms of language use are not necessarily organised along 'language' boundaries, 'language' (especially when appearing as national or standard 'language') can be seen as a particularly powerful and pervasive cultural concept, naturalised and invested with authority through ideological processes.

To sum up, by seeing cognitive and social processes as inseparable, a usagebased perspective allows us to refrain from simply dismissing 'language' as an outdated linguistic ideology, and to instead theorise and trace the complex ways in which 'language' as a sociocultural construct forms part of the social and cognitive realities of speakers. A usage-based perspective on language learning has to include investigating social environments and 'communities' with their discourses and practices, language users' networks and interactions, as well as speakers' individual learning trajectories and subjectivities. We can then ask when and how 'language' is oriented to and made relevant on these different levels. In the following sections, I explore this question by discussing data from interviews with highly proficient speakers of Finnish as a second language. My discussion is based on the premise that my participants' linguistic repertoires comprise a wide range of resources that are the result of their individual learning trajectories. I ask how my participants perceive their social environment, especially with regard to 'language', and what kind of language use they feel is enabled, encouraged or expected of them; how they describe and rationalise their attempts to make sense to themselves and to others when navigating their multilingual networks; and what potential consequences this has for the development of their competence. 


\section{Data and participants}

The data discussed here were gathered during spring and summer 2015 in interviews with adult speakers of Finnish as a second language. Participants were recruited by contacting acquaintances - mostly Finnish speaking foreigners living in the Helsinki area as well as people working in second language teaching or research - who in turn contacted their friends and colleagues. Some were recruited by participants I had already interviewed. The goal was to find speakers with a high and multifaceted level of competence who only started learning Finnish as adults (18 years or older). Participants were required to have lived in Finland for less than 15 years and to use Finnish in various contexts of their everyday life. My choice of participants was partially motivated by the assumption that highly proficient speakers can offer particularly valuable insights into the social aspects of L2 use, because, as Kramsch (2012: 110) points out, their experience reaches well beyond "the usual criteria of communicative competence", i. e. grammatical accuracy and pragmatic appropriateness, and draws attention to issues of identity, legitimacy, and social and cultural power relations. By collecting interview data as well as ethnographic data at a later point, my study also aims to complement earlier research on highly proficient or near-native L2 speakers' social identities, which has often relied on written memoirs (e. g., Pavlenko 2001).

Below I report on interviews with 9 participants from 4 different European countries. The participants were between 25 and 39 years old, had been living in Finland for 5 to 13 years, and all but one had earned a university degree at bachelor's or master's level. All participants grew up in monolingual families in their country of origin but stated that they had learnt 3-4 additional languages on average later in life. In addition to Finnish, they all mentioned English as an additional language, with differing degrees of competence and frequency of use. Other languages mentioned include Russian, Estonian, French, Dutch, German etc. With regard to Finnish, some of the participants had studied Finnish before moving to Finland, while others started learning the language only after relocating. However, for all participants, the language learning process included both formal language education in Finnish and informal language learning with friends, Finnish partners, etc. The participants can thus be described as highly educated multilinguals with a high proficiency at least in their L1 and in Finnish, as well as in other languages (notably English) in some cases. From the perspective of individual repertoires, the participants are able to draw on resources from different 'languages' but also on different stylistic (e. g., academic, colloquial) and professional registers (e. g., linguistics, healthcare). Their upbringing in relatively monolingual L1 environments and their learning of additional languages later in life, however, has also 
made them familiar with contexts of formal language instruction and the still prevailing "monolingual principle" (Cummins 2007). An overview of the participants and their linguistic backgrounds can be found in Table 1 (see Appendix).

Interviews were semi-structured and organised around the topics of multilingualism, linguistic practices and identities. All interviews were conducted in Finnish, except those with German participants, who were interviewed in their and my own L1 German. ${ }^{4}$ Since the interviews only covered the first stage of a larger research project, they were designed primarily to obtain background information about the participants' linguistic backgrounds and learning trajectories, their social networks and linguistic routines. The open character of the interview questions, however, also invited attention to personal experiences, emotions and attitudes.

With regard to participants' observable everyday practices and interactional encounters, the interviews discussed below have to be seen as "secondary data" (Auer 1995). In this context, however, interview data are valuable in at least three ways. First, interviews can be considered "important sources of accounts, which allow glimpses into the beliefs and values and ideologies that inform what people do and why they do it" (Heller 2011: 45). From a usage-based perspective, these beliefs, values and ideologies (as experienced by language users themselves) are highly important because they are part of the social and cultural context in which language learning takes place. Second, interviews can offer insights into linguistic practices performed alone (e.g., thinking, reading; see Section 5.3) that form a considerable part of speakers' everyday engagement with language but are difficult to observe directly. Finally, although interview accounts should of course not be taken for accurate descriptions of actual practices, they provided a useful starting point for engaging participants as “co-researchers" (Boylorn 2008).

Because the following discussion focuses on content, I have omitted pauses, repetitions and nonverbal elements in the translated excerpts. Within the scope of this article, the discussion can be neither representative nor exhaustive. Rather, I will use a few examples to reflect on the relationship between multilingual repertoires and monolingual norms in the daily lives of my participants.

\section{Multilingual speakers in a languagised world}

In this section, I will explore some aspects of how the studied speakers experience the use of their multilingual repertoires in different contexts. I will first

4 I initiated this language choice myself, since the German participants had first contacted me in Finnish which was also the language of my recruitment message. However, all three participants confirmed in the interview that this felt like the most 'natural' language choice in this situation. 
have a closer look at the contexts in which participants use their L1 and are ascribed the status of 'native speakers'.

\subsection{Remaining a 'native speaker'}

In the interviews, participants reported using mostly Finnish with their friends (including partners) in Finland but also stated that they actively maintained relationships with friends and family 'at home' through regular phone calls, electronic communication and visits. Both Finnish and the L1 (and in some cases English, e.g., with international friends) thus play an important role in my participants' social life. However, other than in contexts where the same multilingual resources are shared by many or at least several speakers - e.g., in bilingual communities - most of their Finnish-speaking friends have no or very limited knowledge of participants' L1, whereas friends and family in the home country are not familiar with Finnish. Consequently, the participants experience their Finnish-speaking network and the relationships 'at home' as two geographically, socially and linguistically separate environments.

Some scholars have argued that globalisation and the rise of modern communication technologies have created alternative spaces and communities for language use that defy institutional monolingual norms. With respect to translingual practices, García (2009: 29) claims that "speakers are now free to choose a broader range of language practices than those offered by the immediate community and the school; and they can use them in ways that are not reflected in more institutionalised language practices of schools and official publications." It is indeed likely that the participants in this study engage in such multi- or translingual practices in some contexts, e. g., when using social media. At the same time, modern communication technologies enable them to remain part of the monolingual contexts 'at home', by staying in close touch with their friends and families, or by working with clients in their home country. As Lanza and Svendsen (2007: 279) observe, close contact with friends and family in the home country enabled by modern communication and transportation technologies can also "potentially act as a norm-enforcing mechanism" with regard to migrants' language use. In this way, monolingual norms valid in the home country can remain relevant to everyday language use in the diaspora.

One indicator of the relevance of these monolingual norms is that all participants have a strong experience of their L1 competence 'declining' or being influenced by Finnish. Crucially, for some of the studied speakers, competence in the L1 is an economically important skill, like for those participants who occasionally work as proofreaders or translators: 
(1) Sophie: When I have to really write proper French, it takes me a long time. That is really confusing how I realise that my own mother tongue is not as strong as it was before [...]. And [there are] also a lot of like grammar issues with French that come from my ear being so used to Finnish. One time [...] when I was proofreading, I was like this is wrong, this is wrong, but it was right, it was just the Finnish grammar that made it look wrong. That is really confusing, like what am I anymore, who am I.

(2) Zuzana: Well, in my mother-tongue, which is Czech, I read quite a lot online, I read news and things like that and then I write with friends in the social media and so on. Proper fiction I hardly read in my mother-tongue, but I'm trying to increase that now, because I feel I need to maintain [the language] a bit.

It is hardly surprising that judgments about correctness can be altered by experiences with language (see Hall et al. 2006: 228), or that professional linguistic skills, like the ability to use sophisticated literary language, have to be actively maintained. However, when acting as 'native speakers' in professional contexts, my participants are expected to draw on a monolingual 'native' competence. For instance, the participant working as a translator draws on her whole linguistic repertoire while translating but also has to make sure the translation itself will conform to a certain monolingual standard. In such professional contexts, an important part of participants' repertoires can therefore be rendered invisible or even be experienced as a disruptive influence.

On the whole, my participants seem to feel much less pressure concerning their L1 performance in informal contexts, e.g., when talking to friends and family in their home country. Consider, however, the following statements:

(3) Bianka: I often explain to my parents, 'yeah, you know, that thing' and I explain and then they say the word, but they don't really comment in a mean way. Rather, I once got positive feedback when I ran into an old acquaintance in Hungary and we talked for a long time and s/he was astonished that I don't have an accent and I thought, excuse me, why should I have an accent, I'm still Hungarian.

(4) Julia: It seems silly to me when I just throw in a Finnish word in German in Germany, because no German person will understand me [...]. But it does happen that I think of the Finnish word first. For example the word niin [yes, yeah], that happens very often when I tell someone something or someone tells me something and I 
want to join the conversation then the first thing that comes out is a niin. [...] I found it so annoying when I was still living in Germany and we had this... I think it was in eleventh grade when everybody did an exchange year and came back after a year and suddenly threw in a lot of English words or French words. I thought that was so annoying and so show-off. Now I understand it very well...

So, while friends and family are usually very understanding of the difficulties these participants experience when explaining things relating to the Finnish context, both are aware of the possible consequences of making their multilingual repertoires visible to others: they could either be perceived as having lost their 'native' competence, or their language use could be interpreted as a way of 'showing-off'. The ability to display monolingual competence is thus an important way of showing to friends and family that they are still 'one of them'.

\section{2 (Micro-)contexts for multilingual language use}

The personal networks described so far provide few opportunities for participants to make use of their linguistic repertoires in a more comprehensive way. However, most report that they have at least one or two friends in Finland whom they share their L1 with and who are also fluent in Finnish. In such cases participants state that they predominantly use their L1 with these friends, but that they also draw on Finnish resources when this is convenient, as illustrated by the following example. Earlier in the interview, Bianka (Hungary) had told me that she uses 'mixed language' (sekakieli) with her Hungarian colleagues and friends who are also proficient in Finnish:

(5) KR: Could you explain what you mean by speaking mixed language with your Hungarian friends. What does that mean?

Bianka: Well, it means really mixed sentences [...]. Like when I talk about my work for example, I use a lot of these words and then I putbecause in Hungarian it's easy, because we have suffixes, too, and you just attach a Hungarian suffix to a Finnish word.

KR: $\quad$ I see.

Bianka: Things like that for example. And then we translate into Hungarian, for example, you wouldn't say tehdään niin [let's do that] like Finnish people often say when they agree on something, and we translate that into Hungarian although you usually don't say that at all [...] in Hungarian. That's maybe the two ways. 
KR: $\quad$ But you usually say that in your circle of friends.

Bianka: Yes, [...] I'm sure it sounds really strange to a normal Hungarian, but we're used to saying that now.

Lexical resources associated with Finnish and used in L1-framed conversations are thus described as being either somehow specific to the Finnish context or particularly idiomatic in Finnish, or as belonging to specific contexts that my participants only encountered after having moved to Finland (e. g., job or family related). ${ }^{5}$ It can be argued that this particular and quite restricted form of 'language mixing' is not mere convenience but can also be explained by participants' ideas about language and themselves as language users. For instance, a term's clear relation to the Finnish context can make language-mixing more acceptable within monolingually framed situations (namely that it is language mixing for a good reason). The following excerpt, in which Bianka elaborates on language choice and 'mixed' language use among her Finland-based Hungarian friends, seems to support this:

(6) Bianka: I have two Hungarian colleagues and sometimes they speak entirely in Finnish to one another. And that always annoys me for some reason, like, hello, you're Hungarians and there's just the two of you or it's the three of us, so why... and that annoys me, so we don't do, entire sentences for example. Only [if] it's something that we don't have [in Hungarian] or it is difficult to find a word and then you say it in Finnish in that sentence.

KR: $\quad$ So an entire sentence would be too much?

Bianka: Yes, or maybe if you quote someone... of course, if you quote something from a conversation, for example a conversation at the workplace, then of course, but not if we talk to each other about our own stuff...

Judging from this report, language choice and the degree of 'mixing' are a site of struggle among Bianka's friends. Annoyed by her Hungarian friends' exclusive use of Finnish, she proposes that Finnish resources are only acceptable in such a situation if they are somehow related to Finland, difficult to express in Hungarian, or represent a direct quote form a Finnish conversation, but not for speaking with what she indicates to be her own voice ("if we talk to each other about our own stuff').

5 Interestingly, the interviews with the German participants (conducted in German with both interviewer and interviewee being fluent in Finnish) confirm this pattern. 
Compared to these examples, reports of the use of L1 resources in Finnishframed interactions are much rarer, which is not surprising given that most of the participants' Finnish-speaking contacts have no knowledge of participants' L1. Consider, however, the following statement:

(7) Judit: My friends always laugh at me because I very directly translate a lot of these Hungarian... well, because in Finnish you say for example 'to put the cat on the table' [nostaa kissa pöydälle, to bring up a difficult topic], well, things like that I translate from Hungarian to Finnish and then everybody [asks] what do you mean and what is that. But I always tell them that in this situation I do that on purpose. Of course I try, especially when I write, not to write like that, but often I enjoy it that I use [language] a bit differently and people get used to it. [...] And I like to tell people about it, that I say it because in Hungarian there's a saying like that. [...] I don't necessarily think that's a mistake because I always explain why I said it that way.

Since Judit's friends do not understand Hungarian, she reports translating Hungarian idioms into Finnish as an enjoyable way of using Finnish differently than 'native speakers'. However, because she is aware that this might be interpreted as wrong, she claims to always provide an explanation for the phrase. That she avoids this practice in writing might be due to the fact that writing is seen as more 'official' or because it does not allow any paralinguistic framing. This seems to imply that making L1 resources visible to others as an L2 speaker without raising suspicion of incompetence requires the simultaneous assertion of 'actual' (i. e. monolingual) competence in the L2. By disclosing the reason for using an 'incorrect' phrase, my participant shows that she is well aware of this expression not being part of the Finnish standard and encourages a positive reading of her multilingual competence as enriching and emphasising her individualism.

The examples discussed so far show that the studied speakers claim to routinely engage in multilingual practices. However, their opportunities for using resources across 'language' boundaries seem to be restricted to a relatively small group of contacts, just as their and others' beliefs about language have a profound impact on how multilingual resources can be used. In the case of using Finnish resources in L1-framed conversations, ideologies of an innate and stable 'native' competence force speakers to carefully choose what kind of resources they use and when. The simultaneous construction of an 'obvious' rationale for the use of these resources (e. g., idiomaticity) can be seen as a way 
of investing these linguistic choices with authority. In the rarer case of making L1 resources visible in Finnish conversations, ideologies of what it means to be a 'non-native' speaker (e. g., making 'mistakes' rather than using language creatively) make it necessary to frame such usage as deliberate or enjoyable in order to prove that they are 'competent' in the sense of a monolingual standard. This shows that, from a social perspective, competence is not something that speakers 'have' or 'display' from a neutral ground but something that is simultaneously 'granted' to them against the background of wider-scale beliefs and linguistic expectations.

\subsection{Intrapersonal practices}

In this final subsection, I will take a look at participants' intrapersonal communicative practices, that is "practices such as thinking, planning, and self-reflecting that involve just the individual” (Hall et al. 2006: 232, referring to Vygotsky). Since such practices are not directly monitored by others, I suspected that my participants would make different use of their repertoires than when interacting with others, because this kind of language use would be less influenced by speaker positions and questions of legitimacy. Indeed, when asked what language(s) they used for activities performed alone (I asked, e. g., about thinking, reading books or online news, writing a diary, a shopping list or notes to oneself), all participants stated they used at least two languages (mostly Finnish and the L1, but also English and other languages) on a daily basis, often shifting seamlessly between languages within activities.

For some practices, patterns of language use were reported as being relatively established or following a specific rationale. One participant (Julia, Germany) reported that she used both Finnish and her L1 German for reading news online. However, this was not a daily choice but rather a routine of visiting her preferred websites. Another participant (Sandra, Germany) stated that she read fiction in three languages (Finnish, German and English), but only authors in their original language. For many other activities, however, languages were described as somewhat interchangeable, language choice depending on the concrete situational context as well as the preceding activity. For instance, most participants said they had no preferred language for using search engines online but rather used whichever language was most related to the topic of the search or was thought to lead to the best results. Many also struggled to find a rationale for their language choice in some situations, ultimately attributing it to the 'state of mind' they found themselves in after the preceding activity. The following extract is an example of this: 
(8) Zuzana: When I talk to myself, I talk to myself aloud quite often really, it's usually in Finnish. Of course when I have just been to the Czech Republic or when I have talked to someone on the phone in Czech [...] then I might use Czech when I talk to myself or to the cat, but usually I always use Finnish. Shopping lists I write in Finnish, except when I have looked at some Czech recipe and there the things are written in Czech, then in a way I see them written in Czech and then I write them in Czech for myself as well.

The 'state of mind' explanation was also brought forward by some participants when talking about 'mixed' language use in intrapersonal practices. Here, 'language mixing' was not described as intentional word play but as something that simply "happens". An example of this is the response one participant gave when I asked her, in which language she would write a shopping list for herself:

(9) Sophie: Yeah, that's very mixed, too. Both French and Finnish. Or sometimes there's the French partiti- I mean, the Finni- [laughs] like something with the Finnish partitive, a French word plus the Finnish partitive. And I'm not trying at all to pretend that I have some sort of... that I am so... I don't know... it's not playing around, it's real, it's a real phenomenon that is happening to me.

At first glance, this seems to confirm the hypothesis that, when using language alone, speakers do indeed combine linguistic resources more freely than in social interaction. However, statements like the following show how such language use can also be actively monitored by the participants:

(10) Bianka: I noticed some time that for example with recipes or something, or when I write a shopping list... Today I really had to pay attention to writing it in Hungarian, because I was leaving [for the shop] alone, so it didn't matter. And then I thought, hey, this is going over the top, I want to write it in Hungarian. But my life is quite dominated by Finnish [laughs].

KR: Why did you want to write it in Hungarian then?

Bianka: Well, I don't want it to get rusty, I realise it is getting rusty and then, for example, I sometimes force myself [to use it]. Especially with shopping for some reason, I go there and think to myself what I have to buy, so I wouldn't list the things in Finnish but in Hungarian [in my mind]. 
The interview excerpt shows that speakers can orient to broader language ideologies even in linguistic practices performed alone, and that they can use such instances for trying to shape their linguistic repertoires (here by recalling the Hungarian names of the items on a shopping list). Moreover, it can be argued that my participants' competence is already profoundly shaped by experiences of monolingual language use (e. g., from contexts of formal language instruction, see Section 3), making it challenging to engage in fluid multilingual practices, even when alone. The following excerpt can be seen as an example of this. My participant explains that she 'mixes' Finnish and French resources when writing to-do-lists on her computer. She then shows me her current to-do-list (see Figure 1) and tries to find an explanation for her choice of code in different sections of the list. She first looks for a connection between the French entries and the French context but quickly realises that those entries “don't really concern France”. She then seeks for a syntactical explanation ("maybe they are a bit longer") but dismisses this as well. Again, she states the possibility of the Finnish entries being connected to her "everyday life here" but instantly falsifies this when she discovers entries about "everyday life" written in French. She concludes that the use of both languages in her list is not functionally distributed but has something to do with her "state of mind" when writing the list. Finally, she provides more information on how her lists are written:

Réorganiser les notes

$\square$ Trier les docs dans le dossier Desktop

Effacer les notes qui ne servent à rien dans iphone

$\square$ Trier les rappels dans iphone

$\square$ Préparer les cours de

Faire des archives

YTL

$\checkmark$ Envoyer facture à

$\square$ Apteekki

$\checkmark$ Antihistamiinivalmiste

Nenäsuihke

$\checkmark$ Hyttysmyrkky

$\square$ Harmoniser les noms Spotify, Youtube, Instagram

Télécharger vidéo MTV Huomenta Suomi

Figure 1: Marie's to-do list (extract). 
(11) Marie: Somehow it it annoys me a bit when there's like both French and Finnish, for example in the titles [of the sections]. But of course there are also French titles here, but it annoys me a bit. But I'm a bit of a pedant, if there's a French title and then a Finnish one and then they don't they don't look the same, so then it just...

KR: $\quad$ So do you sometimes correct your own lists?

Marie: Yeah, well at least the titles I change, they can't be in French.

This participant's reported unease with mixing resources that "don't look the same" and her self-description as a "pedant" point to how she herself sees this as a personal (and maybe slightly exaggerated) preference (other participants were indeed more comfortable with this kind of writing). Although the list is not intended for anyone else to see, Marie feels the need to keep languages apart at least for aesthetic reasons and will even go as far as editing what she has already written. I earlier pointed out that translingual language use is often assumed to be a 'natural' ability of multilingual individuals (see Section 2.2). Within a usage-based understanding of linguistic competence, however, linguistic resources are never acquired independently from norms of use, and the knowledge of appropriateness has to be seen as part of speakers' competence. Depending on the context, this can include the skill to separate 'languages' from each other. From this perspective, it can be assumed that it is years of practice in monolingual writing - first in the L1, then in other languages - in a cultural environment shaped by ideologies of separate 'languages' that enable my participant to quickly detect visual 'incongruencies' in the first place and that make her feel "annoyed" at not living up to sociocultural ideals of language use, even in her personal communication. This visual and emotional unease can also be read as an indicator of how language and rules for its use are not just 'stored' in cognition but are essentially embodied (see Busch 2012: 520-521).

To sum up, while my participants experience intrapersonal practices as giving them more freedom to use whatever linguistic resources are convenient to them, even these practices are to some extent influenced by norms of monolingualism and the separation of 'languages'.

\section{Conclusion: Between ideologies and realities}

In this paper, I have examined some aspects of how multilingual speakers move in a languagised world. The discussion shows how speakers' opportunities for making use of their multilingual repertoires can be restricted by social environments 
organised along 'language' boundaries, rendering their multilingualism invisible or even a problem. In situations that allow for a more fluid use of multilingual resources, speakers have to carefully balance the use of these resources against the backdrop of language ideologies as well as their sociolinguistic status (e. g., as 'native speakers' or 'L2 speakers'). Finally, speakers sometimes orient to monolingual norms even in linguistic practices that involve only themselves, which suggests that such norms can also become internalised and embodied, e.g., in the form of an aesthetic sensitivity favouring the separate use of 'languages'.

From a usage-based perspective on linguistic competence, these processes cannot be interpreted as negotiations between the reality of diverse repertoires that do not differentiate between 'languages' on the one hand, and the ideologies of a languagised world on the other. Rather, we have to ask how exactly competence develops in response to the demands and ideologies of the social environment. In some cases, competence will include the ability to draw on resources associated with different 'languages' in different ways, in others, it will include knowing how to keep 'languages' apart and how to successfully display monolingual competence. A usage-based perspective, then, enables us to treat 'languages' as sociocultural constructs, while at the same time acknowledging how, under specific circumstances, these constructs can become part of speakers' competence through experiences with language in a languagised world.

\section{Appendix}

Table 1: Participants in the interview study.

\begin{tabular}{lllrr}
\hline & Participant & L1 & Age & $\begin{array}{r}\text { Length of stay } \\
\text { in Finland in years }\end{array}$ \\
\hline 1 & Alexander & German & 29 & 5 \\
2 & Sandra & German & 39 & 13 \\
3 & Sophie & French & 38 & 10 \\
4 & Zuzana & Czech & 32 & 7 \\
5 & Marie & French & 28 & 5,5 \\
6 & Bianka & Hungarian & 36 & 8 \\
7 & Judit & Hungarian & 28 & 5 \\
8 & Veronika & Czech & 31 & 5 \\
9 & Julia & German & 25 & 7 \\
\hline
\end{tabular}

Note: All names are pseudonyms. 


\section{References}

Auer, Peter. 1995. Ethnographic methods in the analysis of oral communication: Some suggestions for linguists. In Uta M. Quasthoff (ed.), Aspects of oral communication, 419-440. Berlin \& New York: Walter de Gruyter.

Block, David. 2003. The social turn in second language acquisition. Washington, DC: Georgetown University Press.

Blommaert, Jan. 1999. Reconstructing the sociolinguistic image of Africa: Grassroots writing in Shaba (Congo). Text 19(2). 175-200.

Blommaert, Jan \& Ad Backus. 2011. Repertoires revisited: 'Knowing language' in superdiversity. Working Papers in Urban Language and Literacies 67. London: King’s College.

Blommaert, Jan, James Collins \& Stef Slembrouck. 2005. Spaces of multilingualism. Language and Communication 25(3). 197-216.

Boylorn, Robin M. 2008. Participants as co-researchers. In Lisa M. Given (ed.), The Sage encyclopedia of qualitative research methods, 600-602. Los Angeles: Sage Publications.

Busch, Birgitta. 2012. The linguistic repertoire revisited. Applied Linguistics 33(5). 503-523.

Canagarajah, Suresh. 2009. The plurilingual tradition and the English language in South Asia. AILA Review 22. 5-22.

Canagarajah, Suresh. 2011. Translanguaging in the classroom: Emerging issues for research and pedagogy. Applied Linguistics Review 2. 1-28.

Cook, Vivian J. 1991. The poverty-of-the-stimulus argument and multicompetence. Second Language Research 7(2). 103-117.

Cook, Vivian J. 1992. Evidence for multicompetence. Language Learning 42(4). 557-591.

Cook, Vivian J. 1999. Going beyond the native speaker in language teaching. TESOL Quarterly 33(2). 185-209.

Cummins, Jim. 2007. Rethinking monolingual instructional strategies in multilingual classrooms. Canadian Journal of Applied Linguistics 10(2). 221-241.

García, Ofelia. 2009. Bilingual education in the $21^{\text {st }}$ century: A global perspective. Malden, MA: Blackwell.

Gumperz, John. 1986 [1972]. Introduction. In John Gumperz \& Dell Hymes (eds.), Directions in sociolinguistics: The ethnography of communication, 1-25. Oxford \& New York, NY: Blackwell.

Hall, Joan K., An Cheng \& Matthew T. Carlson. 2006. Reconceptualizing multicompetence as a theory of language knowledge. Applied Linguistics 27(2). 220-240.

Heller, Monica. 2003. Globalization, the new economy, and the commodification of language and identity. Journal of Sociolinguistics 7(4). 473-492.

Heller, Monica. 2008. Language and the nation-state: Challenges to sociolinguistic theory and practice. Journal of Sociolinguistics 12(4). 504-524.

Heller, Monica. 2009. Multilingualism and transnationalism. In Peter Auer \& Li Wei (eds.), Handbook of multilingualism and multilingual communication, 539-555. Berlin: Mouton de Gruyter.

Heller, Monica. 2011. Paths to post-nationalism: A critical ethnography of language and identity. Oxford \& New York, NY: Oxford University Press.

Hymes, Dell. 1972 [1971]. On communicative competence. In J. B. Pride \& Janet Holmes (eds.), Sociolinguistics: Selected readings, 269-293. Harmondsworth: Penguin. 
Hymes, Dell. 1986 [1972]. Models of the interaction of language and social life. In John Gumperz \& Dell Hymes (eds.), Directions in sociolinguistics: The ethnography of communication, 35-71. Oxford \& New York, NY: Blackwell.

Hymes, Dell. 1992. The concept of communicative competence revisited. In Martin Pütz (ed.), Thirty years of linguistic evolution: Studies in honor of René Dirven on the occasion of his sixtieth birthday, 31-57. Philadelphia, PA: John Benjamins.

Jørgensen, J. Normann. 2012. Ideologies and norms in language and education policies in Europe and their relationship with everyday language behaviours. Language, Culture and Curriculum 25(1). 57-71.

Jørgensen, J. Normann, Martha S. Karrebæk, Lian M. Madsen \& Janus S. Møller. 2011. Polylanguaging in Superdiversity. Diversities 13(2). 23-38.

Kramsch, Claire. 2012. Authenticity and legitimacy in multilingual SLA. Critical Multilingualism Studies 1(1). 107-128.

Lanza, Elizabeth. 2004 [1997]. Language mixing in infant bilingualism: a sociolinguistic perspective, 2nd edn. Oxford: Oxford University Press.

Lanza, Elizabeth \& Bente A. Svendsen. 2007. Tell me who your friends are and I might be able to tell you what language(s) you speak: Social network analysis, multilingualism, and identity. International Journal of Bilingualism 11(3), 275-300.

Lowie, Wander, Marjolijn Verspoor \& Kees de Bot. 2009. A dynamic view of second language development across the lifespan. In Kees de Bot \& Robert W. Schrauf (eds.), Language development over the lifespan, 125-146. New York: Routledge.

Makoni, Sinfree \& Alastair Pennycook. 2005. Disinventing and (re)constituting languages. Critical Inquiry in Language Studies 2(3). 137-156.

Ortega, Lourdes. 2014. Ways forward for a bi/multilingual turn in SLA. In Stephen May (ed.), The multilingual turn: Implications for SLA, TESOL and bilingual education, 32-54. London: Routledge.

Rymes, Betsy. 2010. Classroom discourse analysis: A focus on communicative repertoires. In Nancy H. Hornberger \& Sandra Lee McKay (eds.), Sociolinguistics and language education, 528-546. Bristol: Multilingual Matters.

Pavlenko, Aneta. 2001. 'In the world of the tradition, I was unimagined': Negotiation of identities in cross-cultural autobiographies. International Journal of Bilingualism 5(3). 317-344.

\section{Bionote}

\section{Katharina Ruuska}

Katharina Ruuska is a PhD candidate at the University of Jyväskylä. Her research focuses on the impact of language ideologies on the everyday linguistic practices of highly proficient adult speakers of Finnish as a second language, with a particular interest in the phenomenon of 'passing for a native speaker'. 